\title{
Path Choice of Urban-Rural Integration System in West China under the Vision of Rural Revitalization
}

\author{
Libin Guo \\ Science and Technology Department, Chongqing University of Education, Chongqing 400065, \\ China; guolb@cque.edu.cn
}

Keywords: Rural revitalization; Urban-rural integration; Path choice

\begin{abstract}
To realize mutual benefit and win-win through the urban-rural integration is the basic requirement of China's rural revitalization strategy, and also a new motive force for rural development in the new era. The task of rural revitalization in west China is even more difficult under the superimposed effect of the unbalanced development between east and west China and the unbalanced development between cities and villages. On the basis of drawing lessons from the advanced experiences of the developed countries on rural revitalization, rural development, rural construction and so on, this paper puts forward the path choice to implement the strategy of rural revitalization in west China in the new era, and puts forward the construction of the coupling pattern and innovation system of "people", "land" and "industry" in rural areas to construct a urban-rural integration system in which workers and peasants promote each other, urban and rural areas complement each other with all-round integration and co-prosperity that conforms to the regional characteristics of the west China.
\end{abstract}

\section{Introduction}

As socialism with Chinese characteristics has entered a new era, and the economic growth and social development have made great achievements, the contradiction between the people's growing need for a better life and the unbalanced and inadequate development has also become the social principal contradiction. Especially with the rapid development of industrialization and urbanization, the lagging of rural modernization has led to significant changes in the structure of urban and rural areas so that the unbalance development between urban and rural areas and the inadequate rural development have become one of the important performance of main social contradictions. Since the implementation of the strategy of "One Belt and One Road" and the development and opening up of western inland, the differences in economic and social development between the eastern coast and the central and western inland areas have been weakened. However, the relevant studies have shown that compared with the different regions and inter-provincial economic difference, the difference within the province contributes more to the regional economic difference in China as a whole. The western development strategy, based on the "point-axis development theory" makes the urban-rural economic difference and polarization of many western provinces show a trend of expansion [1]. Under the superimposed effect of the unbalanced development between the east and west China and between urban and rural areas, the task of rural revitalization in the western region is particularly arduous, and the realization of urban-rural integration is more complicated. Therefore, this paper, drawing lessons from the developed countries' advanced experience such as rural revitalization rural development and rural construction and combining with the unique characteristics of the western region's economic and social development, puts forward the path choice of implementing the strategy of rural revitalization in the new era.

\section{The Enlightenment of Foreign Experience to the Multiple Implementation of Rural Revitalization Strategy in West China}

As urban and rural relationship is the most basic economic and social relationship, scholars at home and abroad have had active discussions from different angles and at different levels regarding rural revitalization, rural construction, rural reconstruction, rural development or combining practice, or research fields. In both developed and developing countries, rural revitalization is a strategy implemented by countries in the world after a certain stage of economic and social development. Developed countries have made beneficial attempts in this regard, which has accumulated rich experience in promoting rural revitalization practice 
together, and can provide some useful reference for us.

The Construction of small towns in American Countryside.

As one of the most urbanized countries in the world, the United States highly advocates the development of rural society through the construction of small towns. In the United States, there are no villages in our traditional sense. In the rural areas of the United States, most of the peasant household live scattered on their own farms. When planning rural areas, the US government will meet the basic needs of the local people and strict the overall layout of rural areas and guarantee "seven accesses and site leveling" in the process of overall rural construction with highway running through them. The funds for rural infrastructure construction are shared by the government and developers. At the same time, the US government began to build "ecological village" very early. The policy of ecological environment was carried out vigorously. It paid great attention to greening, beautifying the rural environment, protecting water source and fresh air, and making people live in harmony with nature. Meanwhile, the US government fully respects and carries forward the local people's life tradition, highlights the inherent distinctive characteristics of the countryside. The countryside of America is full of trees, flowers and grasslands so that there is no shortage of idyllic scenery.

\section{South Korean New Countryside Movement}

In 1970s, in order to promote rural development, South Korea set off a national development strategy with rural development as the core, which is similar to the new rural construction in China. The design and implementation of a series of development projects, with the support of the government, and farmers' autonomy and project development as the basic driving force and bond, drove the peasants to carry out their spontaneous home construction activities and formed a superincumbent national network. After the 1990s, the Korean government formulated a series of policies and measures to support agriculture and develop rural economy, society, culture and education in an all-round way, which made the development of rural society and economy link organically, promote each other and develop harmoniously. After entering the new century, the Korean government has constructed a series of innovative systems to promote the sustainable development of agriculture and rural society. For example, the budget has been substantially increased in the form of "direct payment system", so as to ensure the stable and continuous increase of farmers' production, operation, and income, and support farmers, fishermen annuity, rural development and welfare improvement. At the same time, the Korean government has established and strengthened the position, function and effect of environmental affinity agriculture through legislation, and promote the democracy and legal system building, the construction of social morality, the education of collective consciousness and so on. Through the long-term unremitting efforts of the Korean government, in the last 30 years of urbanization and industrialization, the coordinated development of the urban and rural economy and the synchronous increase of the income of the urban and rural residents have been realized, which has created conditions for easing the social contradictions and promoting rapid economic development.

\section{Japanese Rural Revitalization Movement}

Through the rural revitalization movement, Japan promotes the activation of exchange of human, material and information between the city and the farming and fishing villages, promotes the emergence of new demand, and new economic activities, and drives the second innovation development of urban and rural economy. First, the state took the lead to increase investment in infrastructure, and systematically promote the preparation of the necessary common social foundation such as the rural residential land, community facilities, communication base and so on. Then, the local government took the lead to increase personnel input, continuously carry out the "Rural Building and Reform Countermeasures" since 2002, and implement soft measures, such as the formulation of the whole region revitalization plan, the movement of inhabitants, the training of talents serving for rural creation, the dispatch of special consultants and experts, and so on. The government continuously carries out the official and folk interactive activities, establishes meetings to promote two-way resource flows, organizes and coordinates key activities related to the rural revitalization plan, and establishes links to various relevant information websites aimed at the two-way flow of cooperative resources, strengthens the provision of relevant information, and the sharing of information among members, as well as the review and proposal for the cooperation of special departments and the promotion of two-way flow of resources. The function of ecological culture and landscape environment should be reconstructed, and based on the characteristic beautiful agriculture and fishery village, the rural protection and embodiment area 
should be set up, and the common property of the people would be opened to the urban residents in the form of inheritance.

\section{Strategic Direction of Constructing Western Urban-Rural Integration System}

To carry out the strategy of rural revitalization, we should regard cities and villages as an organic system, promote capital, talent and other elements to gather to the countryside through constructing the coupling pattern and innovation system of "people", "land", and "industry" in rural areas, further promote the coordination and sustainable development of the rural economy, society, culture, education, ecology, and technology systems, gradually break the urban and rural functional regions segmentation pattern, and make cities and villages support and integrate with each other, and make common progress in order to realize the balanced development of agricultural scientific and technological innovation and industrial scientific and technological innovation, realize the goal of synchronous development of new industrialization, informatization, urbanization and agricultural modernization.

Comply with the Requirements of Urban-rural Integration, Improve the Modern Urban and

\section{Rural Planning System.}

The current planning system emphasizes the segmentation of urban and rural areas. However, under the premise of rural revitalization and urban-rural integration, the government should create a new urban-rural integration planning mechanism, break through the existing administrative barriers in urban and rural planning, and form a organically connected global planning system through taking "multiple rules in one" as the overall plan. Focusing on the special regional characteristics of the western region, relying on the industrial function area, the ecological function area and the comprehensive transportation hub, we should overall plan the urban system of the "main functional area+ characteristic town(block)+new community (forest settlement)", mould the space structure with the interaction and integration of historical context, the economic flow, the green corridor and the industrial distribution and integration and form the urban-rural integration development pattern with clear function, organic block linkage, optimized allocation of resources and improved overall efficiency.

Improve the Quality Suitable for Living and Industry, Optimize the Urban and Rural Functional Layout.

The government should take "intensive and high efficiency production space, livable and suitable living space, picturesque scenery in ecological space" as the overall requirement, implement the "cross policy", determine the main function orientation of the sub-region and sub-district, strengthen the interregional and urban-rural functional integration, further enhance the level of connectivity between urban and rural infrastructure, promote the balanced allocation of public service resources, explore the complementary sharing mode of urban and rural ecological resources, accelerate the construction of a homogeneous distribution and equal sharing of urban and rural life networks and the urban and rural ecosystem with landscape coordination and natural succession, gradually break the form of urban and rural functional region segmentation to form a "city in the countryside" development pattern, and explore a new way of urban-rural integration and development.

\section{Promote Industrial Cooperation and Construct Modern Agricultural Ecological Circle}

Focusing on the agricultural innovation chain, talent chain, supply chain, value chain, industrial chain, the government should insist on reform and innovation to establish a scientific and systematic agricultural institutional system, adhere to openness and tolerance to establish an open system of regional cooperation for common development, adhere to the policy guidance to establish an orderly flow of elements supply system, adhere to the market operation to establish an economic and efficient agricultural value system, insist on industry crossing to set up a modern industrial system of integration and development, promote a more open allocation of elements, the deep integration of three industries, and urban and rural economic integration development to form an agricultural ecosphere with regional coordination, industry high-end, green circulation, diversified subjects, efficient supply, synergy and linkage and compound functions, and strive to increase the efficiency in agriculture, increase farmers' income, and realize rural development.

Build Self-government, Law-government and Rule of Virtue, Combine to Innovate Urban and Rural Community Governance.

The government should attach importance to the inheritance and development of rural culture and 
strengthen the identity and cultural confidence of professional farmers, continuously improve the policy guidance and operational efficiency of urban and rural public service supply system and enhance the sense of access of the masses, take the new-type community as the carrier to promote the deep integration and benign interaction of tangible elements such as village appearance, the natural environment, etc. and the invisible elements such as cultural characteristic, the value idea and so on, speed up the construction of an organic unity and coordination community of village (community) autonomous organization, social organizations and new farmers to form a rural governance system taking party building as the guide, autonomy as the basis, rule of law as the guarantee and the rule of virtue as support.

\section{The Choice of Construction Path of Western Urban-rural Integration System in the Perspective of Rural Revitalization}

The development of urban and rural areas has experienced the stage of promoting cities by agriculture and driving rural areas by cities, and it has reached a new stage of urban-rural linkage and integration development. Under the background of rural revitalization, the west China should work hard to break down the obstacles of the system and mechanism of urban-rural integration and development, construct a reasonable flow mechanism of urban and rural elements, promote the market-oriented allocation of resources factors such as "people", "land" and "money" in urban and rural areas, and promote the formation of a new type of urban-rural relationship with mutual promotion between workers and peasants, the complementary between urban and rural areas, comprehensive integration and common prosperity.

\section{Strengthen the Guidance of Rural Revitalization Planning}

The government should optimize the urban and rural ecological spatial arrangement of production and life, take the districts and counties (autonomous county) (hereinafter referred to as the district and county) as the core point of rural revitalization, take the characteristic small town as the joint point of rural revitalization, and regard the characteristic village as the key point of rural revitalization, and make overall planning for urban and rural industrial development, population distribution, public services, land utilization, ecological protection and rural construction planning. Under the framework of the overall urban and rural planning and the overall land use planning, the district and county, town, and village planning should be carried out in accordance with the requirements of concept first, classified propulsion, and highlighting features, so as to implement the principle of "integration of multiple rules and regulations.", precisely promote village planning and village construction planning, improve the level of rural planning and construction to better show the natural beauty and humanistic beauty of the countryside.

Promote joint construction and sharing, interconnection and interworking of urban and rural inf rastructure

The government should vigorously promote the reticular infrastructure construction oriented to the needs of the "three rural issues", adhere to overall planning, urban-rural integration, seize weak and key breakthroughs, speed up the lifting and upgrading of rural transport, water conservancy, information and energy infrastructure, build urban and rural connectivity, safe and efficient infrastructure network system. What's more, the government should carry out the "four good rural roads" construction project to form the convenient and unimpeded traffic network system from the city to the countryside, and from the market to the field, implement rural residents drinking water consolidation and upgrading project to improve rural drinking water network, carry out farmland water conservancy construction project to construct the agricultural irrigation water supply network system in accordance with the actual situation in hilly and mountainous areas, implement the "information countryside" construction project to construct safe and efficient information communication network with rational layout, balanced development and perfect function in urban and rural areas, implement the digital village strategy to promote the construction of "mobile Internet village" and "Internet town" in all-round way. According to the local conditions, the government should push forward the transformation and demonstration pilot of rural power grid, and upgrade and transform the rural power grid with insufficient power supply capacity. Besides, the government should carry out the gas supply project of special small towns to improve the existing gas pipeline network of characteristic small towns, and to improve the stability and reliability of gas supply in characteristic small towns. 


\section{Promote Rational Flow of Urban and Rural Resource Factors}

First of all, the government should innovate the system and mechanism, create a good environment, promote urban talents, capital and other resources to "go to the mountains area and countryside" to bring together the strength of rural revitalization. Secondly, the government should implement the outstanding agricultural scientific research talent program and outstanding young agricultural scientists project, strengthen knowledge updating and training of the agricultural technicians at grass-roots level, and implement the special employment scheme for agricultural technology extension service. Thirdly, the government should improve the interest incentive mechanism and promote pilot reform of the rights and interests of agricultural scientific research achievements, actively cultivate new-type professional farmers, establish and improve the system of professional farmers and supporting policies, innovate training methods, and develop new-type professional farmers' training, such as production and management type, professional skill type, social service type, etc. What's more, the government should establish an effective incentive mechanism to encourage and attract people from all walks of life to participate in rural construction with nostalgia as the link, strengthen urban and rural land resources overall protection, adjust and perfect the use range of land transfer income and increase the proportion of land transfer income used for rural revitalization. Moreover, the government should optimize the rural investment environment, stabilize policy expectations, and actively guide industrial and commercial capital to the countryside, improve the level of financial services, promote the coordination and linkage of monetary and fiscal policies, allocate more financial resources to the key areas and weak links of rural economic and social development to ensure the steady and sustained growth of agriculture-related loans.

\section{Reference}

[1] Mu Jin, How do Countries in the World Develop Rural Areas? [J]. "China Financier"2018, 2.

[2] Lan Feng, Urban-rural Integration, Rural Revitalization [J]. “Urban and Rural Construction”2018.4.

[3] Tang Renwu, The implementation path and Strategy of the New Era Rural Revitalization Strategy [J]. "People's Forum: Academic Frontier", 2018. 2.

[4] Wang Mingtian, Urban and Rural Integrated Planning of Counties and Cities under the Background of New Urbanization [J]. "The Small Town Construction"2012, 11.

[5] Luo Dan; Liu Tao;Li Wenming, Ramming up the System and Mechanism Guarantee of Rural Revitalization[J]. 'Farmers' Cooperatives in China", 2018. 5.

[6] Liu Yansui, Urban-rural Integration and Rural Revitalization in the New era of China [J]. "Geography Journal", 2018. 3.

[7] Li Shuishan, The New Village Movement in South Korea and Its Beneficial Enlightenment to the Construction of New Countryside in China [J]. "Journal of Shenyang Agricultural University (Social Science Edition)", 2012. 3.

[8] Lin Liuxing, The Exploration and Analysis of the Path of Implementing the Strategy of Rural Revitalization [J]. 'Modern Agricultural Science and Technology”, 2018. 3. 